Revista Iberoamericana. Vol. LXIII, Núms. 178-179, Enero-Junio 1997; 61-70

\title{
LA NACIÓN HISPANOAMERICANA COMO PROYECTO RACIONAL Y NOSTALGIA MITOLÓGICA: ALGUNOS EJEMPLOS DE LA POESÍA
}

\author{
POR \\ Nicolas Shumway \\ The University of Texas at Austin
}

Pocos debates, en nuestros días por lo menos, evitan polarizaciones constructivistas y esencialistas. En las polémicas sobre el origen y la sobrevivencia de las naciones modernas esta polarización se percibe en dos posturas que resumo a continuación. Por un lado está el pensamiento que llamaré empírico o racional que ve la formación nacional como un acto de voluntad colectiva, sea por un plebiscito o por una asamblea constituyente. Es decir, es una construcción que ocurre en un momento dado mediante la intervención de personas históricamente identificables. ${ }^{1}$ Por otro lado está el pensamiento esencialista que mantiene que, a grandes rasgos, toda colectividad humana muestra ciertos elementos míticos que le dan sentido de una identidad compartida. Estos elementos, con variantes desde luego, se encuentran en toda comunidad humana, sea esta colectividad una aldea medieval, una tribu selvática, o una nación moderna. Esta recurrencia de elementos (que en otra parte he llamado "nacionemas" o "tribalemas") tiene por lo menos dos explicaciones posibles señaladas por los términos primordialismo y perennialismo. ${ }^{2}$ Para el primordalista, los

\footnotetext{
${ }^{1}$ Los practicantes más conocidos de este planteo son E.J. Hobsbawm, Benedict Anderson, y Ernest Gellner. Hobsbawm comienza su fecundo estudio con una insistencia casi agresiva de que no había naciones en el sentido moderno de esa palabra antes de 1780. Afirma que "The modern sense of the word [nation] is no older than the eighteenth century, give or take the odd predecessor" (Hobsbawn 3). Se basa en el argumento -que a mí me parece más bien un axioma que un argumento- de que la nación tiene que ser congruente con un Estado político. Es decir, no hay naciones sin estados. Desde luego, esta postura tiene antecedentes. Por ejemplo, John Locke (sin duda uno de los "odd predecessors") en su "Second Treatise on Civil Government" escrito en 1689 ya había proclamado que las sociedades políticas resultan del consenso de varios individuos que quieren incorporarse en una comunidad de la que se benefician todos sus integrantes. Benedict Anderson en su conocido estudio acepta las bases de Hobsbawm, pero trata de explicar los mecanismos de la formación nacional, recurriendo más que nada a los aportes de la imprenta capitalista (passim.).

${ }^{2}$ Aquí sigo el modelo de Anthony D. Smith en The Ethnic Origins of Nations. Sugiere Smith, sobre todo en el primer capítulo, "Are nations modern?", que los argumentos de Hobsbawm y Gellner confuden la escala con la esencia, y que Anderson confunde el vehículo con la sustancia (Smith 618). Igual que la postura racional/empírica, el planteo de Smith, aunque basado en métodos de antropología moderna, resuena con ecos de Johann Herder, Montesquieu en L'esprit des lois, y no pocos poetas que se han empeñado en imaginar para sus naciones orígenes sobrenaturales, genealogías divinas y gloriosos futuros predestinados.
} 
tribalemas nacieron con la especie y sobreviven en el subconsciente colectivo; de ahí su virtual universalidad en toda comunidad humana. El perenialista no especula sobre las causas de los nacionemas, pero insiste en que las investigaciones comparativas revelan que éstos ocurren con regularidad en todas las generaciones y en todas las culturas. ${ }^{3}$

Mi propósito en este trabajo es explorar dos tendencias en el pensamiento de la independencia que podrían llamarse "constructivistas" y "esencialistas". La corriente constructivista se identifica fácilmente en casi todos los intentos legislativos de la época. La premisa tácita de las asambleas constituyentes partía precisamente de una postura tal, pues asumían los constituyentes que a través de un acto de voluntad colectiva una comunidad podría constituirse como un Estado moderno. Eso es más o menos lo que sugiere Bolívar en su famoso discurso a los constituyentes de Angostura de 1819:

Nosotros ni aún conservamos los vestigios de lo que fue en otro tiempo: no somos Europeos, no somos Indios, sino una especie media entre los Aborígenes y los Españoles. Americanos por nacimiento y Europeos por derechos, nos hallamos en el conflicto de disputar a los naturales los títulos de posesión y de mantenernos en el país que nos vio nacer, contra la oposición de los invasores. Así nuestro caso es el más extraordinario y complicado (Bolívar 84).

Aquí, Bolívar efectivamente niega que los Hispanoamericanos tengan una historia, o por lo menos una historia que sirva para los fines de construir una nación moderna y liberal. Más adelante en el mismo discurso, Bolívar afirma que la mayoría de los individuos que ocupan el espacio venezolano son incapaces de ser un Pueblo soberano, o si se me permite usar sus propias palabras, "Nuestros pobres conciudadanos tendrán que enrobustecer su espíritu mucho antes que logren digerir el saludable nutritivo de la Libertad" (Bolívar 86).

En resumidas cuentas, Bolívar afirma que en la América Hispánica no existía una historia del tipo que utilizaron los constructores de las naciones-estado europeas; y por otra parte niega que exista en Hispanoamérica, en ese momento por lo menos, un pueblo capaz de gobernarse. Es decir, si se me permite intercalar una frase que escribió el argentino Esteban Echeverría unos treinta años después en su Ojeada retrospectiva, había que esperar "que el pueblo fuese por fin pueblo" (Echeverría 106). Bolívar más adelante aconseja a los

\footnotetext{
${ }^{3}$ Esto no quiere decir que Hobsbawm descuente la importancia de tales elementos pre-existentes. De hecho, declara que la primera etapa de la evolución nacional consiste en una "proto-nación" cuyos elementos son precisamente una etnia, lengua, religión, historia compartida, o fronteras naturales que podrían contribuir a la formación de una nación estado moderna, pero que de por sí no constituyen una nación propiamente dicha. Al final de esta primera etapa la proto-nación tiene que alcanzar un estado de iminencia que Hobsbawm denomina Threshold o Umbral (31). Cuando suficientes ingredientes de una nación posible (lengua, religión, territorio, memoria colectiva, etc.) muestran bastante vigor e intensidad para sostener un proyecto nacional, se puede decir que esta proto-nación ha llegado al Threshold y está preparada para la segunda etapa que es la intervención de una élite que produce un proyecto nacional (Hobsbawm 46-78). Por ejemplo, a mediados del siglo XIX, varios principados alemanes podrían considerarse proto-naciones, pero sólo la intervención de Bismark y su grupo pudo construir un Estado de esas proto-naciones. Lo mismo se podría decir de la Italia de Cavour. El salto de proto-nación a nación-estado, sin embargo, no es automático, como muestran algunos de los nacionalismos más feroces: los Kurdos, por ejemplo.
} 
constituyentes que tendrán que "echar los fundamentos a un Pueblo naciente" porque ese pueblo capaz de ser soberano todavía no existe (Bolívar 86). Aquí, entonces, el Libertador parece reforzar un concepto constructivista de la nación: igual que el pueblo de Echeverría, se tiene que hacer. El Estado incipiente es, entonces, un espacio abierto que espera una intervención legislativa para formar una nueva nación.

Sin embargo, los poetas de la época (y el mismo Bolívar en ciertos momentos) desmienten esta idea de que las naciones que están por hacerse sean tan nuevas; de hecho, revelan una fuerte nostalgia por viejas mitologías que justificaban las primeras colectividades, y no en pocas ocasiones intentan construir una identidad colectiva que se parece mucho más a una historia mitológica que a la tábula rasa invocada por Bolívar. Al apoyo de esta tesis dedico el resto de esta nota.

Casi toda historia tribalista empieza con una explicación sobrehumana, sea su nombre Dios o algo metafísico. No es atípica la descripción en el Génesis del llamamiento de Yavé a Abram:

Y dijo Yavé a Abram: Salte de tu tierra y de tu parentela, y de la casa de tu padre, para la tierra que te indicaré. Y haré de ti una nación grande, $\mathrm{y}$ te bendeciré, $\mathrm{y}$ engrandeceré tu nombre, que será una bendición. Y bendeciré a los que te bendijeren, y a los que te maldijeren maldeciré; y serán benditas en ti todas las familias de la tierra (Génesis 12, 13).

De este corto pasaje podemos identificar cinco elementos esenciales del paradigma tribal, es decir, cinco tribalemas. Primero, el origen o la fuerza causante de la tribu es de naturaleza metafísica, abstracta, más allá de los cinco sentidos humanos. En el caso de Abram (cuyo nombre más adelante se cambia a Abraham como señal de su convenio con Dios), esa fuerza causante (o mytomoteur para usar un término de Smith) era Yavé, la deidad tribal que más adelante se volvería el Dios del judaísmo, del cristianismo y del Islam. ${ }^{4}$ Otro tribalema que surge de este pasaje es el vínculo entre la tribu y una tierra prometida, que es no sólo un espacio donde la tribu vive su historia sino también un elemento sobrenatural en la identidad colectiva de la tribu: un lugar de orígenes, milagros y sueños del retorno del exilio. En una palabra, la Patria. Un tercer tribalema que detectamos en el pasaje citado es la conexión entre el patriarca y su descendencia, que a la vez constituye un vínculo de linaje compartido y reúne a todos los herederos en una familia. La tribu por lo tanto es una familia, y los hijos de la familia nacen con esta identidad colectiva, no la adquieren. De esta forma, la familia (el patriarca y su descendencia) se convierte en un patriarcado que trasciende a las generaciones particulares. Un cuarto tribalema se percibe en la promesa que pone a la colectividad por encima de otros pueblos ("Bendeciré a los que te bendijeren, y a los que te maldijeren maldeciré"). De esta forma la tribu se convierte en el pueblo escogido, el pueblo del convenio. Y por fin, la tribu tiene un destino especial ("y serán benditas en ti todas las familias de la tierra"), el cual implica a la vez una tarea divina y un gran destino colectivo.

\footnotetext{
${ }^{4}$ Esta fuerza causante, sin embargo, no tiene que ser una deidad. Como Auguste Comte señala en su condena de la metafísica, conceptos no menos abstractos que Dios -el contrato social de Rousseau o los derechos inalienables de Thomas Jefferson, por ejemplo- pueden servir la misma función que Yavé, y son igualmente inverificables.
} 
Estos mismos triablemas se notan en numerosos poemas que alaban la independencia. Consideremos por ejemplo el comienzo de "A la independencia" del poeta hondureño Juan José Trinidad Reyes Sevilla:

\author{
¡LIBERTAD, LIBERTAD! ¡Don del cielo! \\ Tú por siempre de Honduras serás \\ La deidad que venera y adora \\ Ofreciendo el incienso en tu altar (10).
}

Es decir, el proyecto de independencia y la consecuente formación de las nuevas naciones ya han sido consagrados por Dios, de manera que la lucha por la libertad es de alguna forma un intento de recuperar lo perdido y llegar a lo predestinado. Vemos una imagen parecida a la de Trinidad Reyes en la primera estrofa de la Marcha Patriótica de Vicente López y Planes, publicada en 1813 y proclamada más adelante el himno nacional argentino:

Oíd, mortales, el grito sagrado:

¡Libertad!; ¡Libertad!; ¡Libertad!”

Oíd el ruido de rotas cadenas;

ved en trono a la noble Igualdad (9).

Esa divinidad (o mytomoteur) puede ser bíblica, o el poeta puede servirse de otros seres divinos, romanos, aztecas o incásicos, como vemos en la cita a continuación, también del himno argentino:

De los nuevos campeones los rostros

Marte mismo parece animar;

la grandeza se anida en sus pechos,

a su marcha todo hacen temblar (12).

Con palabras casi idénticas, José María Heredia en “A los hijos de Anáhuac” de 1823, su famosa denuncia de Iturbide, escribe:

\footnotetext{
¡Sagrada libertad! ¡Cómo en su seno

Sentirá el Anáhuac tus beneficios,

Y altares te alzará de gozo lleno! (1:97).
}

¿Por qué sagrado? Y ¿por qué está sentada la noble libertad en un trono? Lo que vemos aquí es un aspecto que con frecuencia aparece en la poesía de la Independencia. Es innegable que la lucha independentista y los primeros intentos de fundar naciones fueron enmarcados en el iluminismo. Sin embargo, por algún motivo, el grito de ese fin racional e iluminista tiene que ser "sagrado", de la misma manera que el lugar de donde procede esa libertad sagrada tiene que ser un trono divino. Dicho sea de otra manera, lo que vemos aquí a nivel retórico es un residuo de —o por lo menos una nostalgia por - una autoridad divina y metafísica, tal y como la que autorizó a Abraham. 
Otro tribalema que acabamos de ver en el mito fundacional de la Casa de Israel es la idea de la nación como familia cuyos miembros comparten un linaje y descienden de un mismo patriarca. Y otra vez este tribalema es una constante de la la poesía de la Independencia. Consideremos por ejemplo otras líneas del himno argentino de López y Planes:

\author{
Se conmueven del Inca las tumbas \\ y en sus huesos revive el ardor, \\ lo que ve renovando a sus hijos \\ de la Patria el antiguo esplendor (12-13).
}

La referencia al Inca sugiere que la verdadera inspiración de la independencia es el Dios-Inca que, igual que Yavé, fue hecho hombre y vivió eternamente entre los suyos a través de su descendencia. También hay que notar que Lópezy Planes ve la lucha insurgente como una continuación de la lucha de los indígenas, y que los hijos de la Patria son descendientes del Inca, hijos de este suelo americano, es decir, un patriarcado que lucha por recuperar su patrimonio.

Estos intentos de ver al Inca como patriarca espiritual de la lucha independentista se ven en muchos escritos de la época. Consideremos, por ejemplo, el comienzo que José Joaquín Olmedo da a su famoso "La victoria de Junín" de 1825 donde hace una explícita referencia a Dios "que ... en el cielo impera" y Bolívar que "en la tierra [es] árbitro de la paz y de la guerra" (10). Pero lo que es más, Olmedo, igual que Lópezy Planes, vincula la lucha independentista con las primeras deidades americanas:

Venció Bolívar, el Perú fue libre, y en triunfal pompa Libertad sagrada en el templo del Sol fue colocada (Olmedo 10).

En estas líneas, la libertad se escribe con mayúscula; es decir, se personifica, como el nuevo monarca, un monarca sagrado que ocupa el trono del Dios Sol y que de alguna forma es el Dios Sol. Se trata del mytomoteur de la lucha y de las naciones que están por formarse. Más adelante en el poema de Olmedo, el Padre del universo, el Dios Sol, es cómplice en la batalla que interviene a favor de los independentistas:

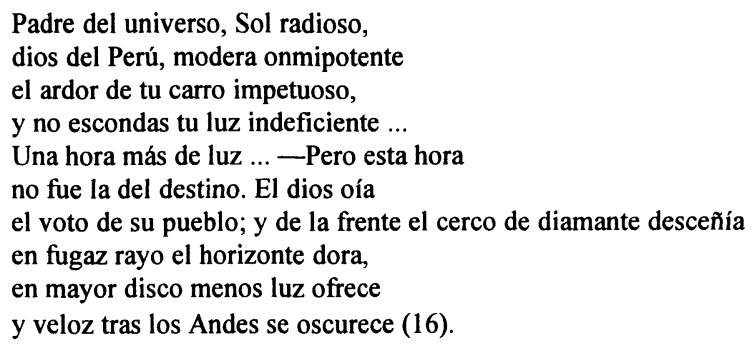

Sin duda, el ejemplo más claro en el poema de Olmedo de este deseo de volver a unirse con la familia sagrada, fundando una genealogía nueva, se ve en la aparición de Huayna 
Capac. Bien conocido es el motivo narrativo de esa inclusión: al estar en medio de la composición del poema, Olmedo recibió noticias de la victoria decisiva del General Sucre en Ayacucho, una victoria que Olmedo por motivos obvios quería conectar con el triunfo de Bolívar en Junín. De ahí la aparición del Inca que, con poderes sobrenaturales, puede anunciar el triunfo de Sucre - sin obligar a Olmedo a re-escribir todo el poema. Pero más allá de esta necesidad narrativa, la aparición del Inca reitera tribalemas como los del patriarca y del pueblo escogido, que en la proyección de Olmedo incluye todos los pueblos de Hispanoamérica. Unos ejemplos:

Miró a Junín y plácida sonrisa vagó sobre su faz. "Hijos — decía— generación del sol afortunada, que con placer yo puedo llamar mía, yo soy Huayna Capac, soy el postrero del vástago sagrado; dichoso rey, mas padre desgraciado" (18).

Más adelante Huayna Capac vincula el espacio de la lucha (la tierra santa) con otras luchas y mitologías indígenas:

Y nuestro suelo, que ama sobre todos el Sol mi padre, en el estrago fiero no fue, joh dolor! Ni el solo, ni el primero: que mis caros hermanos el gran Guatomozín y Motezuma conmigo el caso acerbo lamentaron de su nefaria muerte y cautiverio (19).

$\cdots$

¡Oh campos de Junín ... ¡Oh predilecto

Hijo y Amigo y Vengador del Inca! ¡Oh pueblos que formáis un pueblo solo y una familia, y todos sois mis hijos! Vivid, triunfad ..." (20).

En resumidas cuentas, Olmedo reúne en estas líneas tribalemas de la fuerza causante, la tierra sagrada, la genealogía privilegiada y un destino divino.

Tales tribalemas también son constantes del ya citado poema de José María Heredia “A los hijos de Anáhuac". Veamos, por ejemplo, cómo vincula el poeta cubano la lucha contra el emperador Agustín I (Iturbide) con la lucha de los indígenas contra Hernán Cortés:

Tales los frutos son joh mejicanos!

Que ledos cogeréis si generosos

Las frentes levantáis, y valerosos

El imperio destruís de los tiranos.

De Moctezuma y Ahuitsol el grande,

Y Guatemuz magnánimo las sombras

Se lanzan de sus tumbas polvorosas,

$\mathrm{Y}$ revolando en torno del tirano 
Le amenazan furiosas,

Y de terror le llenan: caiga, caiga

Ese trono fatal que con su peso

Va a abrumar a Anahuac y a destruiros.

A la alma libertad álcense altares,

Y la opulencia y paz serán sus frutos,

Y rendirán a Méjico tributos

Del Norte y Sur los apartados mares (Heredia 99).

Hasta el más "racional" de nuestros fundadores intelectuales, Andrés Bello, participa en esta fabricación de tribalemas americanos. Por ejemplo, en su largo poema "Alocución a la poesía" de 1823, que es a la vez una serie de fragmentos de un poema inédito titulado "América", Andrés Bello invoca casi todos los mitos, o todos los tribalemas que ya hemos visto en otras partes. En "Alocución a la poesía" la poesía, en lugar de ser una estructura literaria, es más bien un instrumento epistemológico que permite al poeta ver la América real, espiritual, pre-existente y potencial. Lo que ve Bello en ese trance poético es un multitemático panorama de América, que va desde los fundadores divinos del imperio incásico hasta los más recientes héroes de la lucha independentista. La fuerza causante que en Bello corresponde al Yavé fundador del antiguo testamento se ve en una serie de alusiones a un paraíso americano perdido, cuya recuperación es la meta de las luchas independentistas. Por ejemplo:
las riquezas de los climas todos
América, del Sol joven esposa,
del antiguo Océano hija postrera,
en su seno feraz cría y esmera (Bello 59-61).

Más adelante habla de todas las grandes ciudades de América - Buenos Aires, Quito, Bogotá y Tenochtitlán como entes pre-existentes, ciudades que vivían en espíritu y en potencial mucho antes de su fundación material. Pero lo que es más, insiste en que en esa existencia pre-histórica y edénica, "La libertad sin leyes florecía, / todo era paz, contento y alegría" (Bello 115-116). Es decir, la lucha independentista tiene como base mitológica la recuperación de un paraíso perdido.

Otro tribalema al que hemos hecho referencia sin indagaciones es el de la tierra prometida, el espacio sagrado, el lugar del nacimiento divino, el suelo patria. Notemos por ejemplo las líneas que encabezan el poema "A José Trinidad Cabañas" de José Trinidad Reyes:

No es sin razón que el hondureño estado

Parezca envanecido con la gloria

De ser tierra fecunda que ha brotado

Héroes muy dignos de eternal memoria (Reyes 8)

O más adelante 
¿Y no se ha de gloriar si de su seno
Vio salir al gigante de la ciencia,
Al hondureño Valle, todo lleno
De saber, de cordura y de prudencia ...
Pero, entre todo, su placer corona
El haber producido de sus entrañas
Al héroe favorito de Belona,
Al inmortal e intrépido CABAÑAS ... (Reyes 9).

Lo notable de estas líneas es que Cabañas no es hijo de la patria sino de la tierra. Por lo tanto, su existencia de alguna forma fue predestinada por ella. Uno casi se atrevería a decir que la existencia de esa tierra santa no pudo menos que producir a un Cabañas.

La propia causa sagrada les da a sus conductores el derecho a pedir sacrificios, igual que Dios le pidió a Abraham la vida de su hijo heredero (Gen. 21:1-18). Lo que es más, la autoridad para exigir sacrificios se manifesta precisamente en aquella persona que puede demandar que sus fieles lo sigan aun hasta la muerte. Consideremos, por ejemplo, la descripción que hace Olmedo de Bolívar:

¿Quién es aquel que el paso lento mueve
sobre el collado que a Junín domina?
¿Que el campo desde allí mide, y el sitio
del combatir y del vencer desina?
...
y a los más bravos a morir condena,
cual águila caudal que se complace
del alto cielo en divisar la presa
que entre el rebaño mal segura pace?
...
¿Quién sino el hijo de Colombia y Marte? (11).

Bolívar autorizado por su sagrada causa puede pedir a los compatriotas la muerte porque al hacerlo sólo está cumpliendo con el destino que le asignó la historia mitológica. Como dice Olmedo más adelante:

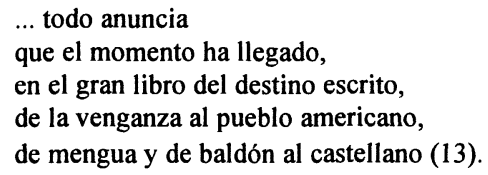

Por último, ningún paradigma de tribalemas puede ser completo sin una profecía, es decir, sin una referencia análoga a la promesa que hace Yavé de que por medio de la estirpe de Abraham serían bendecidas todos los pueblos del mundo. Algunos de los ejemplos que ya hemos visto se podrían considerar proféticos. Sin embargo, en otros textos se hace más explícito. Consideremos, por ejemplo, estas líneas del himno argentino: 


\begin{abstract}
El valiente argentino a las armas corre, ardiendo con brío y valor: el clarín de la guerra, cual trueno, en los campos del Sud, resonó. Buenos Aires se une a la frente de los pueblos de la ínclita Unión, y con brazos robustos desgarran al ibérico altivo León (16).
\end{abstract}

Deducimos de estas líneas que el destino de la Argentina es ponerse "a la frente" de los pueblos hispanoamericanos en la lucha libertadora, y tal vez más adelante actuar como rectora y ejemplo del resto del continente. ${ }^{5}$

Para concluir: describí al comenzar un paradigma de dos posturas opuestas que nos pueden ayudar en nuestras discusiones de las identidades colectivas, sean de familia, tribu o nación. La primera de ellas es una posición constructivista o racional/empírica que ve la nación como una construcción contingente que responde a las necesidades materiales y políticas del momento y que resulta de un acto de voluntad colectiva. La segunda es esencialista, primordialista o perennialista y sugiere que las naciones modernas no son sino una nueva manifestación de sentimientos y paradigmas muy antiguos. Bolívar parece confirmar una postura constructivista en su aparente creencia (en los textos citados en este trabajo por lo menos) de que las naciones hispanoamericanas no tienen un pasado útil y que tienen que hacerse, inventarse, improvisarse siguiendo en el mejor de los casos pautas racionales e iluministas a través de actos constituyentes y legislativos. Luego, analicé varios poemas de la Independencia para mostrar que, por más racional y liberal que fuera la empresa independentista, su poesía no carecía de vínculos con un pasado mucho más remoto, un pasado mítico que se manifiesta en tribalemas tales como origen divino, familia sagrada, y destino glorioso.

Las naciones hispanoamericanas nacen entre estos dos impulsos contrarios, uno de extremada modernidad y otro que muestra una gran nostalgia por las certezas del pasado. Aunque he descrito estas dos tendencias como impulsos contrarios, a la larga no serán más que dos faces necesarias de una sola empresa. Es decir, la nación puede ser un proyecto racional pero requiere la fuerza de mitos tribalistas para sobrevivir.

\footnotetext{
${ }^{5}$ Otro poeta argentino posterior a López y Planes, Olegario Andrade, dará expresión definitiva a este supuesto destino argentino en su poema "La Gran Argentina" de 1867 donde se lee

¡Es mi patria! Mi patria. Yo la veo

A vanguardia de un mundo redimido,

De un mundo por tres siglos amarrado,

Que, cual bajel en mar desconocido,

Rompiendo las cadenas del del pasado

Se lanza con audacia

Cargado de celestes esperanzas,

Al puerto de la santa democracia. (44-45)
} 


\section{Obras Citadas}

Anderson, Benedict. Imagined Communities. 2a edición. London: Verso, 1991.

Andrade, Olegario. Obras poéticas. Eleutorio F. Tiscornia, ed. Buenos Aires: Academica Argentina de Letras, 1943.

Bello, Andrés. Obras. Oscar Sambrano Urdaneta, ed. Caracas: Colección Clásicos Venezolanos de la Academia Venezolana de la Lengua, 1939.

Bolívar, Simón. "Discurso de Angostura". De Moreno a Sarmiento: Ensayistas de Nuestra América. Susana Rotker, ed. Buenos Aires: Editorial Losada, 1994. 81-113.

Echeverría, Esteban. Ojeada retrospectiva sobre el movimiento intelectual en el Plata desde el año 37. Incluido en Dogma socialista. 1846. Buenos Aires: El Ateneo, 1946.

Gellner, Ernest. Nations and Nationalism. Oxford: Basil Blackwell, 1883.

Heredia, José María. Poesías, discursos y cartas. Fernando Ortiz. ed. 2 tomos. La Habana: Colección de Libros Cubanos, 1939.

Hobsbawm, E.J. Nations and Nationalism Since 1780: Programme, Myth, Reality. $2^{\circ}$ edición. Cambridge: Verso, 1990.

López y Planes, Vicente. "El himno argentino". La Lira Argentina (París, 1824).

Olmedo, José Joaquín. Poemas escogidos. Bogotá: La Oveja Negra, 1986.

Reyes Sevilla, Juan José Trinidad. Antología. Tegucigalpa: Departamento de Publicaciones y Artes Gráficas de la Secretaría de Cultura, 1991.

Shumway, Nicolas. "Raúl Scalabrini Ortiz and his Reconstruction of the Argentine Tribe that Never Was". Annals of Scholarship 11 (1995): 84-101.

Smith, Anthony D. The Ethnic Origins of Nations. Oxford: Blackwell Publishers, 1986. 